\title{
Tensile Strength Study of Stainless-Steel using Weibull Distribution
}

\author{
Md Shahnewaz Bhuiyan ${ }^{1}$, Tanzida Anzum², Forhad-Ul-Hasan ${ }^{3}$ and M. Azizur Rahman ${ }^{4}$ \\ 1 Department of MPE, Ahsanullah University of Science and Technology, Dhaka, Bangladesh \\ ${ }^{2}$ Cumilla Cantonment, Cumilla, Bangladesh \\ ${ }^{3}$ Bogra Cantonment, Bogra, Bangladesh \\ ${ }^{4}$ Department of MPE, Ahsanullah University of Science and Technology, Dhaka, Bangladesh \\ emails: ${ }^{* 1}$ newaz.mpe@aust.edu; ${ }^{2}$ tanzidaanzum@gmail.com, ${ }^{3}$ forhad15eb@gmail.com; and ${ }^{4}$ azizur777@gmail.com
}

\section{ART ICLE INFO}

Article History:

Received: $03^{\text {rd }}$ June 2020

Revsed: $11^{\text {th }}$ August 2020

Accepted: $18^{\text {th }}$ August 2020

Published: $16^{\text {th }}$ December 2020

\section{Keywords:}

Weibull Distribution

Tensile Strength

Stainless Steel

Reliability

\begin{abstract}
A B S T RAC T
In the present study, the distribution pattern of the ultimate tensile strength of 304-grade stainless steel was investigated using a two-parameter Weibull distribution function. During tensile testing, it was observed that the ultimate tensile strength varied from specimen to specimen (ranges from 878 to 1006 $\mathrm{MPa}$ ). The results have revealed that the distribution pattern of the tensile strength can be described by the two-parameter Weibull distribution equation. Moreover, the fracture statistics of the stainless steel were examined by plotting the survival probability of the specimen against the applied stress to the specimen. It has been observed that the relationship between the survival probability and the applied stresses can be described by the Weibull model. It also provides design engineers with a tool that will help them to present the necessary mechanical properties with confidence.
\end{abstract}

\section{INTRODUCTION}

Bangladesh enjoyed GDP growth of $8.1 \%$ in 2019 and is set to continue at a fast pace in the near future (United Nations, 2020). The dramatic rise in GDP has resulted in the rapid development of infrastructures and the construction industry has seen stellar growth with a rate of $16.25 \%$ (Islam et al., 2016). It has been reported that Bangladesh will need to construct approximately 4 million new houses annually over the next twenty years to meet the future demand for housing (Bony \& Rahman, 2014). It is noteworthy that most of the construction practice in Bangladesh is concentrated on reinforced concrete (RCC), which affects the environment directly such as global warming, the depletion of natural resources, waste generation and pollution etc. According to the Department of Environment (DoE) and the World Bank, traditional brick-making industries account for $56 \%$ of air pollution in Dhaka city (Islam, 2015). Hence to reduce air pollution, the Bangladesh government has decided to phase out conventional bricks by 2025 from all construction works (Rahman, 2019). From this point of view, sustainability construction concepts get more importance nowadays, where stainless steel is used as a building material due to durable, recyclable, and reusable characteristics (Aksel \& Eren, 2015). In this context, the demand for steel in loadbearing structural applications has been gradually increasing in Bangladesh, mainly owing to their favourable properties such as high strength, better strength to weight ratio, attractive appearance, high fire and corrosion resistance, ability to retain its strength even at high temperatures, fabricability, weldability and so on (Monrrabal et al., 2019; Wang et al., 2019; Monteiro et al., 2017; Feng et al., 2019; Khatak et al., 1996). In recent times, the steel is found to use for a range of structural applications in Bangladesh including:

1. Cladding and roofing applications in the transport sector for a load-bearing member, for example for bus frames (Chakma, 2019).

2. Prefabricated steel structures for different purposes such as setting up factories, multistoried buildings, power plants and bridges, readymade garment factories, textile mills, pharmaceuticals industry (Nur, 2016).

3. Concrete filled stainless steel tube (CFSST) where a rectangular or circular cross-section steel tube is filled with concrete used in various constructions (Sanaullah et al., 2019). 
Therefore, mechanical properties such as strength is very important for the structural and architectural application of steel. Generally, conventional macro tensile tests are commonly used to evaluate mechanical properties such as yield strength, ultimate tensile strength, and ductility. To allow for effective comparison on macroscopic tensile test results, specific details (such as (i) shapes and sizes of the specimen, (ii) straining rates, (iii) methods of measurements, and (iv) data analysis, etc.) of the standard tensile test have been formulated. ASTM-E8/E8M (ASTM E8/E8M-16ae1, 2013) provides full descriptions of testing methods. Based on the macroscopic viewpoint, the mechanical properties of metallic materials are considered homogeneous. However, in the real material, a considerable amount of scattering is observed. The scatter in mechanical properties results from various uncertainties of different origins: (i) the variations in physical or chemical features during manufacturing processes (Azeez et al., 2019), (ii) microstructure stochasticity due to thermo-mechanical processing (such as rolling and extrusion) and heat treatments (Birbilis et al., 2006; Király et al., 2018), (iii) machining and preparation method of the specimen resulting in the variation of residual stresses (SungHo et al., 2010), (iv) variation of bulk defects (Azeez et al., 2019). As a result, the mechanical properties vary from specimen to specimen, even though nominally identical specimens were tested under the same loading conditions (such as loading mode, speed). This indicates that the tensile testing data are not deterministic rather statistical. Hence, the inherent scatter behaviour of tensile properties needs to be assessed probabilistically.

In recent years, the Weibull distribution function has been extensively used for assessing the mechanical properties (both static and dynamic) of metallic materials (Hallinan et al., 1993; Bedi et al., 2009). One of the main reasons is that the probability density function of the Weibull distribution has a wide variety of shapes. For example, when the shape parameter is equal to 1 , it becomes the two-parameter exponential function, whereas when the shape parameter is equal to 3 , the function can approximate a normal distribution. Thus, the Weibull distribution has been proven to be useful to describe the statistical behaviour of tensile strength of many materials, such as ceramic (Glaeser et al., 1997), metal matrix composites (Fukui et al., 1997), fatigue properties of metallic materials (Evans et al., 1983; Mohd et al., 2015; Wang et al., 2001; Bhuiyan et al. 2016). In the context of engineering design and reliability of structures, a good understanding of the scattering behaviour of the ultimate tensile strength of stainless steel may shed light on their safe utilization in design and manufacturing. Therefore, in the present study, the variation of the tensile strength of 304 stainless steel has been analysed using the Weibull distribution function. Finally, the reliability of the material in terms of ultimate tensile strength was presented in graphical form.

\section{Experimental Procedure}

\section{A. Material and Specimen Preparation}

The material used in the present study was a 304 Grade stainless steel plate (with composition (mas\%) 0.0243 0.0268C, $\quad 0.334 \sim 0.352 \mathrm{Si}, \quad 7.86 \sim 7.90 \mathrm{Ni}$,
$1.41 \sim 1.42 \mathrm{Mn}$, $0.0242 \sim 0.0252 \mathrm{P}$

$0.0056-0.0057 \mathrm{~S}$ $18.23 \sim 18.25 \mathrm{Cr}, \quad 0.154 \sim 0.152 \mathrm{Mo}, \quad 0.0804 \sim 0.0821 \mathrm{Co}$, $0.144 \sim 0.145 \mathrm{Cu}, 0.0035 \sim 0.0036 \mathrm{Ti}, 0.0973 \sim 0.0976 \mathrm{~V}$ ) from STEELTECH company and was kindly supplied by the Civil Engineering Department of the Military Institute of Science and Technology (MIST).

From the supplied rectangular 304 stainless steel pipe, tensile test specimens with dimensions $136 \mathrm{~mm}$ (total length, $\mathrm{L}$ ), $6 \mathrm{~mm}$ (gauge width, W), and $2 \mathrm{~mm}$ (thickness, T) were machined using a CNC milling machine, following the ASTM-E8 standard (ASTM E8/E8M-16ae1, 2013). The specimen geometry is shown in Figure 1.

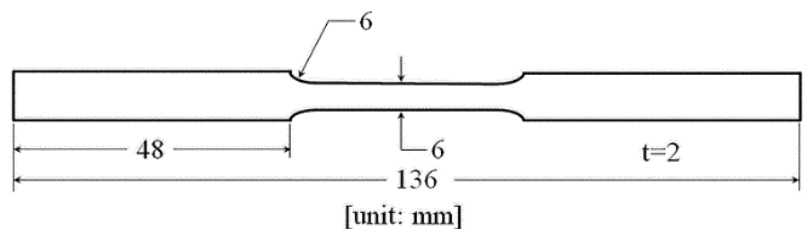

Figure 1: Geometries of mechanical test specimens

\section{B. Tensile Testing Procedure}

In total 10 specimens were prepared for tensile testing. Prior to tensile testing, the width and thickness of each specimen were measured at three locations in the gauge section, and an average cross-section area is calculated. Each specimen was then broken in a universal tensile testing machine with a crosshead speed of $1 \mathrm{~mm} / \mathrm{min}$.

For metallographic examination, samples were polished with 280 to 1500 grit emery papers in laboratory air. In the final polishing step, a 3-micron diamond paste was used. The freshly polished specimen was then etched using a solution containing $20 \mathrm{~mL}$ nitric acid and $60 \mathrm{~mL}$ hydrochloric acid following ASTM 407-07 (ASTM standard 407-07, 2005). The specimens were then observed under an optical microscope.

\section{Theoretical Background}

Based on the weakest-link hypothesis, Weibull proposed a simple distribution function for strength, $\sigma$. Its twoparameter form takes the form (Weibull, 1951):

$F\left(\sigma_{i} ; \sigma_{0}, m\right)=1-\exp \left[\left(-\frac{\sigma_{i}}{\sigma_{0}}\right)^{m}\right] \sigma_{0}>0, m>0$

where $F\left(\sigma_{i} ; \sigma_{0}, m\right)$ is the probability of failure, $\sigma_{0}$ is the characteristic tensile strength (alternatively referred to as scale parameter) where $63.2 \%$ of samples fail $(36.8 \%$ survival probability for samples stressed at loading equal to $\left.\sigma_{0}\right), \sigma_{i}$ is the variable (ultimate tensile strength in the present study), and $m$ is the slope of the curve known as shape parameter (alternatively referred to as Weibull modulus) and is a measure of data scattering and the scale parameter $\sigma_{0}$.

The Weibull modulus, $m$, is estimated using one of the three methods: (i) linear regression, (ii) maximum likelihood, and (iii) moments. However, the commonly used method is linear regression because of its simplicity and relative ease in use (Tiryakioğlu, Hudak, \& Ökten, 2009).

By taking the natural logarithm of both sides of Equation (1) twice yields: 
$\ln \left[\ln \left(\frac{1}{1-F\left(\sigma_{i} ; \sigma_{o}, m\right.}\right)\right]=m \ln \left(\sigma_{i}\right)-m \ln \left(\sigma_{o}\right)=m x+c$

In Weibull statistics, the following four probability estimators are commonly used (Bergman, 1984; Datsiou et al., 2018):

$$
\begin{aligned}
& F\left(\sigma_{i} ; \sigma_{0}, m\right)=\frac{i}{n+1} \\
& F\left(\sigma_{i} ; \sigma_{0}, m\right)=\frac{i-0.5}{n} \\
& F\left(\sigma_{i} ; \sigma_{0}, m\right)=\frac{i-0.3}{n+0.4} \\
& F\left(\sigma_{i} ; \sigma_{0}, m\right)=\frac{i-0.375}{n+0.25}
\end{aligned}
$$

where $i$ is the index of the ascending, $n$ is the sample size (10 in the present study).

Bergman (1984) reported that probability estimators given by Equation (3d) should be used for a small sample size $(n<20)$. Therefore, in the present study, probability estimators defined by Equation (3d) is used to assign a probability of failure to each ultimate tensile strength data point.

The Weibull modulus, $m$, and the characteristic tensile strength, $\sigma_{0}$, can be obtained by plotting $\ln \left[\ln \left(\frac{1}{1-F\left(\sigma_{i} ; \sigma_{o}, m\right.}\right)\right]$ against $\ln \left(\sigma_{i}\right)$. After taking a linear regression of the data point, the slope of the regressed line is the Weibull modulus, $m$, and the intercept is $m \ln \left(\sigma_{o}\right)$.

By fitting a straight line or applying the least square method to $\ln \left[\ln \left(\frac{1}{1-F\left(\sigma_{i} ; \sigma_{o}, m\right.}\right)\right]$ as a function of $\ln \left(\sigma_{i}\right)$, the Weibull modulus $m$ is the slope and the scaling parameter or characteristic tensile strength can be determined from the intercept

\section{RESULTS AND DISCUSSION}

\section{A. General Mechanical Properties}

Figure 2 shows the optical microstructure for the material used in this study. A typical step structure is observed. C. A. Della-Rovere et al. (2013) and A Bahrami et. al. (2019) also reported similar microstructures of 304-grade stainless steel. As reported earlier that in total ten tensile tests were performed and corresponding ten stress-strain curves were recorded for each material. A typical stress-strain curve is shown in Figure 3. It is found that the tensile strength ranges from $878 \mathrm{MPa}$ to $1006 \mathrm{MPa}$, inferring that the ultimate tensile strength appears to vary from specimen to specimen. Table 1 and Table 2 lists the basic statistical properties of ultimate tensile strength and yield strength of the material used in this study. Note that the coefficient of variation $(\mathrm{COV}=$ Standard Deviation $(\sigma) /$ Mean $(\mu) \times 100)$ is about $4.3 \%$ for ultimate tensile strength, and $7.6 \%$ for yield strength. Kweon et al. (2020) reported that the ultimate tensile strength of 304 stainless steel is in the range of 579 to $750 \mathrm{MPa}$. But our investigated material showed about 1.751.90 times higher value of ultimate tensile strength that was reported by Kweon et al. (2020). The observed difference might have resulted due to random experimental errors such as variation in width and thickness in the gauge section, machining of specimen resulting in the variation of residual stresses, microstructural heterogeneity in the gauge section. Since the specimens were prepared using a CNC milling machine, hence all the specimens used in this study were identical in shape and size. Therefore, it is reasonable to assume that the variation of width and thickness in the specimen's gauge section does not influence the observed high value of ultimate tensile. It is well established that during machining because of tool-material interactions, the generated surface is affected through roughness, hardness, residual stress distribution and thereby, influence the mechanical properties of the manufactured parts (Kumar et al., 2017; Ben Fredj et al., 2006; Gürbüz et al., 2017; Ma et al., 2018). H. Sutanto (2007) investigated the characteristics of residual stresses during $\mathrm{CNC}$ milling machining and observed that very high compressive residual stress $(-375$ $\mathrm{MPa}$ ) was induced at the surface of the work material. $\mathrm{H}$. $\mathrm{H}$. Zeng et al. (2017) investigated the residual stresses in microend milling considering sequential cuts effect and found compressive residual stresses were induced by milling operations. Therefore, based on the above discussion, it is speculated that compressive residual stresses were also induced during the CNC milling machining. However, the surface residual stress is not measured in the present study. Hence, it can be inferred that both microstructural heterogeneity and the milling machining induced high compressive residual stresses resulted in higher ultimate tensile strength (about 1.75-1.90 times) in the studied material. Furthermore, for precise and accurate characterization of tensile properties, it is instructive to use a more advanced technique such as electro-discharge machining (EDM) for specimen preparation.

Table 1

Statistical Properties of the Ultimate Tensile Strength

\begin{tabular}{ccc}
\hline \hline $\begin{array}{c}\text { Mean value } \\
\text { (MPa) }\end{array}$ & $\begin{array}{c}\text { Standard deviation } \\
\text { (MPa) }\end{array}$ & $\begin{array}{c}\text { Coefficient of } \\
\text { variation (CV) }\end{array}$ \\
\hline 941 & 40.4 & $4.3 \%$ \\
\hline \hline
\end{tabular}

Table 2

Statistical Properties of The Yield Strength

\begin{tabular}{ccc}
\hline $\begin{array}{c}\text { Mean value } \\
\text { (MPa) }\end{array}$ & $\begin{array}{c}\text { Standard } \\
\text { deviation (MPa) }\end{array}$ & $\begin{array}{c}\text { Coefficient of } \\
\text { variation (CV) }\end{array}$ \\
\hline 577 & 44 & $7.6 \%$ \\
\hline \hline
\end{tabular}

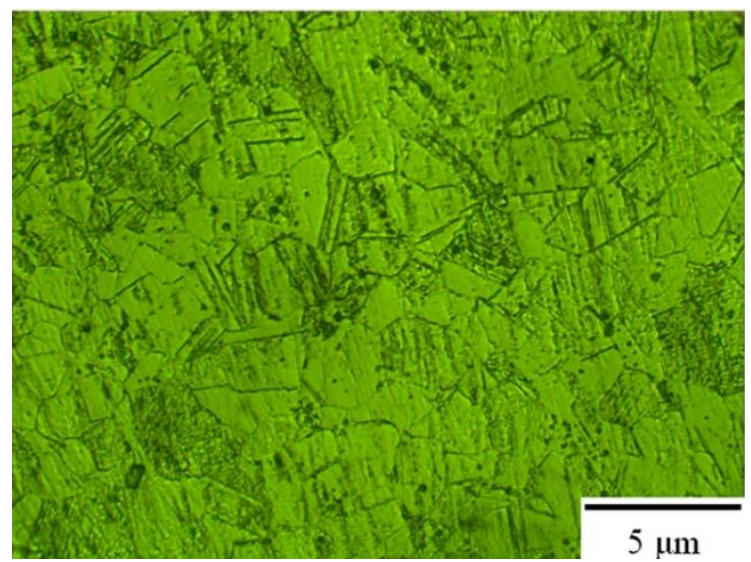

Figure 2: Optical microstructure of 304 stainless steel 


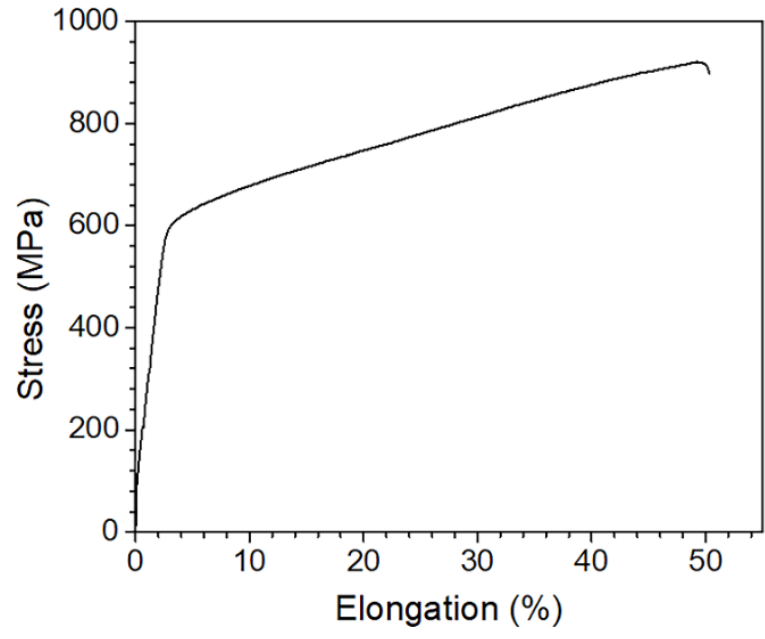

Figure 3: Typical stress-strain curves obtained in the room temperature tensile test

\section{B. Statistical Analysis of Tensile Data}

Figure 4 shows the two-parameter Weibull plot of ultimate tensile strength data. The linear regression model with the regression line is also shown in Figure 4. It can be noted that a good linear relationship was observed which suggested that the distribution pattern of the ultimate tensile strength can be reasonably approximated by the Weibull distribution equation.

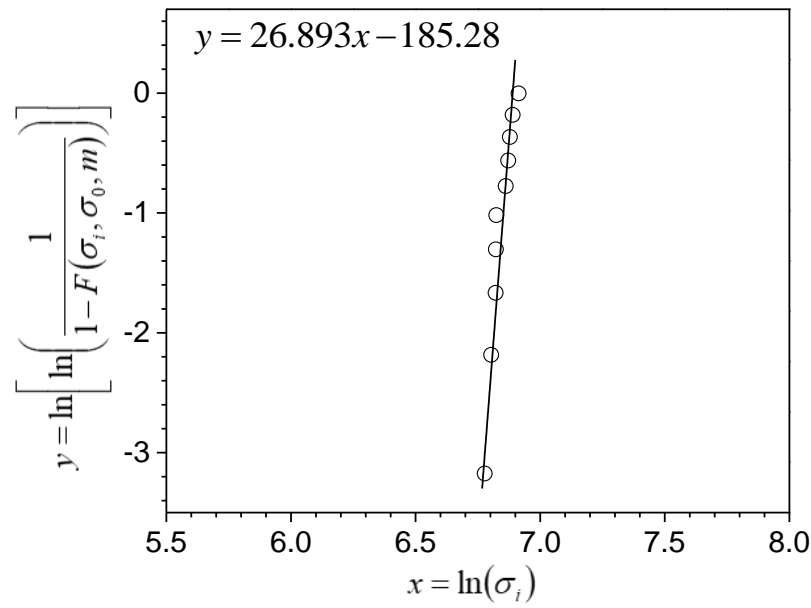

Figure 4: Two-parameter Weibull plot for ultimate tensile strength data

The obtained Weibull distribution parameters such as the Weibull modulus, $m$, the characteristics tensile strength, $\sigma_{o}$, are listed in Table 2. The slope of the line is 26.893, which is the value of the Weibull modulus. Generally, the shape parameter (or Weibull modulus), $m<1.0$ indicates that the material has a decreasing failure rate, $m=0$ indicates a constant failure rate, and $m>1.0$ indicates an increasing failure rate. Our obtained value $m=26.893$ clearly indicates that the material tends to fracture with a higher probability for every unit increase in applied tensile load. As mentioned earlier that the parameter $\sigma_{0}$ is the characteristics tensile strength and as a theoretical property $F\left(\sigma_{i} ; \sigma_{0}, m\right)=0.368$. Based on Table 2, the value of $\sigma_{0}$ is about 982. Therefore, using the value of $\sigma_{i}=\sigma_{o}=982$ and $m=26.893$, $R\left(\sigma_{i} ; \sigma_{0}, m\right)=R\left(982 ; 982,26.893=\exp \left[\left(-\frac{\sigma_{i}}{\sigma_{0}}\right)^{m}\right]=\right.$
0.368 , indicating that $36.8 \%$ of the tensile tested specimens have a fracture strength of at least $982 \mathrm{MPa}$.

Table 2

Parameters of two-parameter Weibull distribution

\begin{tabular}{ccc}
\hline \hline Parameter & Symbol & Values \\
\hline Shape parameter & $m$ & 26.893 \\
Constant term & $c$ & 185.28 \\
Scale parameter & $\sigma_{0}=e^{\frac{c}{\beta}}$ & 982 \\
\hline \hline
\end{tabular}

The Weibull reliability distribution curve for tensile strength is shown in Figure 5. It is observed that the tensile strength values of less than $750 \mathrm{MPa}$ are highly reliable. For a more certain assessment, let us consider 0.95 and 0.9 reliability levels. Using these values in Equation (2), the equation is solved for $\sigma_{i}$ and the fracture strength values obtained were $879 \mathrm{MPa}$ and $903 \mathrm{MPa}$, respectively. More specifically, the material will fracture with 0.90 probability for tensile stress of $903 \mathrm{MPa}$ and similarly will fracture with 0.95 probability for tensile stress of $879 \mathrm{MPa}$.

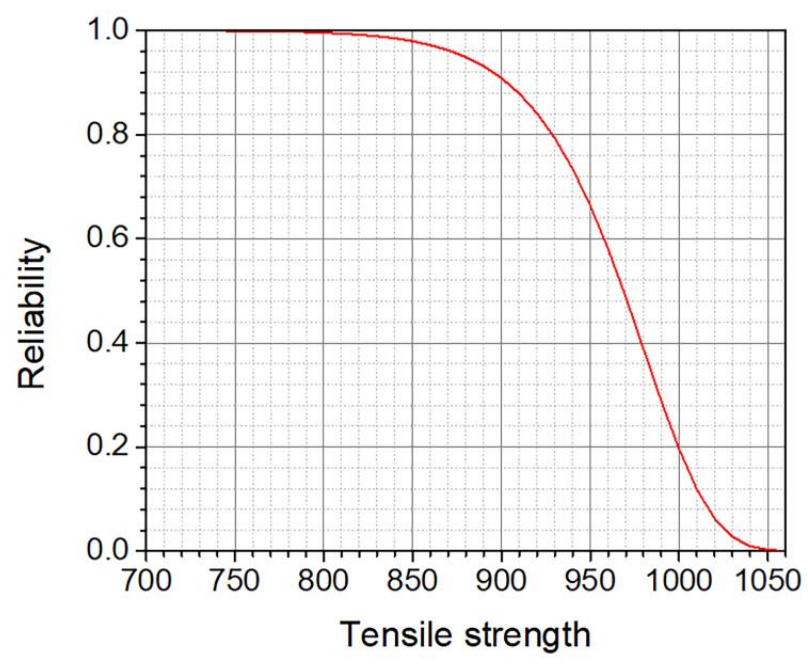

Figure 5: Weibull reliability distribution for tensile strength

\section{CONCLUSIONS}

In the present study, the distribution pattern of the ultimate tensile strength of 304-grade stainless steel was investigated. The main conclusions obtained are summarized as follows:

1. The ultimate tensile strength of 304 stainless steel appears to vary from specimen to specimen. The tensile strength ranges from $878 \mathrm{MPa}$ to 1006 $\mathrm{MPa}$

2. The distribution pattern of the ultimate tensile strength can be reasonably described by the twoparameter Weibull distribution equation.

3. The characteristic tensile strength, $\sigma_{o}$, obtained is about $982 \mathrm{MPa}$. Furthermore, the Weibull 
modulus $(\mathrm{m})$ for the investigated material is found to be 26.893 inferring that the materials tend to fracture with a higher probability for every unit increase in applied tensile load.

4. The fracture statistics of the stainless steel were examined by plotting the survival probability of the specimen against the stress applied to the specimen. It has been observed that the relationship between the survival probability and the applied stresses can be described by the Weibull model. It also provides design engineers with a tool that will help them to present the necessary mechanical properties with confidence. For example, with a 0.90 reliability level, it was observed that the tensile strength of the present material will be $903 \mathrm{MPa}$.

5. The varying tensile strengths of stainless steel are due to their inherent internal structures, inferring that there is no specific strength value to represent mechanical behaviour. This study undoubtedly raises questions of assuming the tensile strength as an average of the experimental results. Therefore, the distribution and reliability of mechanical properties especially tensile strength must be described by the probability of function for their safe utilization in design and manufacturing.

\section{ACKNOWLEDGEMENTS}

The authors would like to thank the Civil Engineering Department, Military Institute of Science and Technology (MIST) and STEELTECH Company for supplying the 304grade stainless steel material. The expert assistance by the technical staff in the Civil Engineering department for conducting the tensile test and the Mechanical Engineering department for preparing the specimen at MIST is also sincerely appreciated.

\section{REFERENCES}

Aksel, H., \& Eren, O. (2015). A Discussion on the Advantages of Steel Structures in the Context of Sustainable Construction. New Arch-International Journal of Contemporary Architecture, 2(3), 46-53. https://doi.org/10.14621/tna.20150405

ASTM standard 407-07. (2005). ASTM 407-07, Standard Practice for Microetching Metals and Alloys, ASTM International, West Conshohocken, PA, 2007, 1-21. https://doi.org/10.1520/E0407-07.2

ASTM E8/E8M-16ae1. (2013). Standard Test Methods for Tension Testing of Metallic Materials. ASTM International, 1-27. (Extracted on Dec. 02, 2020). Source: http://www.astm.org/Standards/E8.htm

Azeez, S., Mashinini, M., \& Akinlabi, E. (2019). Road map to sustainability of friction stir welded $\mathrm{Al}-\mathrm{Si}-\mathrm{Mg}$ joints using bivariate weibull analysis. Procedia Manufacturing, 33, 3542. https://doi.org/10.1016/j.promfg.2019.04.006

Bahrami, A., \& Taheri, P. (2019). A Study on the Failure of AISI 304 Stainless Steel, 1-7.
Bedi, R., \& Chandra, R. (2009). Fatigue-life distributions and failure probability for glass-fiber reinforced polymeric composites. Special Issue on the 12th European Conference on Composite Materials, ECCM 2006, 69(9), 1381-1387. https://doi.org/10.1016/j.compscitech.2008.09.016

Ben Fredj, N., Sidhom, H., \& Braham, C. (2006). Ground surface improvement of the austenitic stainless steel AISI 304 using cryogenic cooling. Surface and Coatings Technology, 200(1617), $4846-4860$ https://doi.org/10.1016/j.surfcoat.2005.04.050

Bergman, B. (1984). On the estimation of the Weibull modulus. Journal of Materials Science Letters, 3(8), 689-692. https://doi.org/10.1007/BF00719924

Birbilis, N., Cavanaugh, M. K., \& Buchheit, R. G. (2006). Electrochemical behavior and localized corrosion associated with $\mathrm{A} 17 \mathrm{Cu} 2 \mathrm{Fe}$ particles in aluminum alloy 7075-T651. Corrosion Science, 48(12), 4202-4215. https://doi.org/10.1016/j.corsci.2006.02.007

Bony, S. Z., \& Rahman, S. (2014). Practice of Real Estate Business in Bangladesh: Prospects \& Problems of High-rise building. IOSR Journal of Business and Management, 16(7), 01-07. https://doi.org/10.9790/487x-16740107

Chakma, J. (2019). Steel industry booming on mega projects. (Extracted on Dec. 02, 2020). Source: https://www.thedailystar.net/business/news/steel-industrybooming-mega-projects-1735855

Datsiou, K. C., \& Overend, M. (2018). Weibull parameter estimation and goodness-of-fit for glass strength data. Structural Safety, $\quad 73, \quad$ 29-41. https://doi.org/10.1016/j.strusafe.2018.02.002

Della-Rovere, C. A., Castro-Rebello, M., \& Kuri, S. E. (2013). Corrosion behavior analysis of an austenitic stainless steel exposed to fire. Engineering Failure Analysis, 31, 40-47. https://doi.org/10.1016/j.engfailanal.2013.01.044

Evans, A. G. (1983). Statistical aspects of cleavage fracture in steel. Metallurgical Transactions A, 14(7), 1349-1355. https://doi.org/10.1007/BF02664818

Feng, Q. B., Li, Y. B., Carlson, B. E., \& Lai, X. M. (2019). Study of resistance spot weldability of a new stainless steel. Science and Technology of Welding and Joining, 24(2), 101-111. https://doi.org/10.1080/13621718.2018.1491378

Fukui, Y., Yamanaka, N., \& Enokida, Y. (1997). Bending strength of an Al-Al3Ni functionally graded material. Composites Part B: $\quad$ Engineering, 28(1-2), 37-43. https://doi.org/10.1016/s1359-8368(96)00018-2

Glaeser, A. M. (1997). The use of transient FGM interlayers for joining advanced ceramics. Composites Part B: Engineering, 28(1-2), 71-84. $\quad$ https://doi.org/10.1016/s13598368(97)00039-5

Gürbüz, H., Şeker, U., \& Kafkas, F. (2017). Investigation of effects of cutting insert rake face forms on surface integrity. International Journal of Advanced Manufacturing Technology, 90(9-12), 3507-3522. https://doi.org/10.1007/s00170-016-9652-7

Hallinan, A. J. (1993). A Review of the Weibull Distribution. Journal of Quality Technology, 25(2), 85-93. https://doi.org/10.1080/00224065.1993.11979431

Islam, F. A. S., Alam, M. M.. I., \& Barua, S. (2016). Investigation on the uses of steel as a sustainable construction material in Bangladesh., International Journal of Scientific Engineering and Applied Science (IJSEAS), 2(1), 41-52.

Islam, M. A. (2015). Corrosion behaviours of high strength TMT steel bars for reinforcing cement concrete structures. Procedia Engineering, 125, 623-630. https://doi.org/10.1016/j.proeng.2015.11.084

Khatak, H. S., Gnanamoorthy, J. B., \& Rodriguez, P. (1996). Studies on the influence of metallurgical variables on the stress corrosion behavior of AISI 304 stainless steel in sodium 
chloride solution using the fracture mechanics approach. Metallurgical and Materials Transactions A: Physical Metallurgy and Materials Science, 27(5), 1313-1325. https://doi.org/10.1007/BF02649868

Király, M., Antók, D. M., Horváth, L., \& Hózer, Z. (2018). Evaluation of axial and tangential ultimate tensile strength of zirconium cladding tubes. Nuclear Engineering and Technology, 50(3), 425-431. https://doi.org/10.1016/j.net.2018.01.002

Kumar, P. S., Acharyya, S. G., Rao, S. V. R., \& Kapoor, K. (2017). Distinguishing effect of buffing vs. grinding, milling and turning operations on the chloride induced SCC susceptibility of 304L austenitic stainless steel. Materials Science and Engineering A, 687, 193-199. https://doi.org/10.1016/j.msea.2017.01.079

Kweon, H. D, Kim, J. W., Song, O., \& Oh, D. (2020). Determination of true stress-strain curve of type 304 and 316 stainless steels using a typical tensile test and finite element analysis. Nuclear Engineering and Technology, (in press). https://doi.org/10.1016/j.net.2020.07.014

Ma, Y., Zhang, J., Feng, P., Yu, D., \& Xu, C. (2018). Study on the evolution of residual stress in successive machining process. International Journal of Advanced Manufacturing Technology, 96, 1025-1034. https://doi.org/10.1007/s00170017-1542-0

Mohd, S., Bhuiyan, M. S., Nie, D., Otsuka, Y., \& Mutoh, Y. (2015). Fatigue strength scatter characteristics of JIS SUS630 stainless steel with duplex S-N curve. International Journal of Fatigue, $\quad 82, \quad 371-378$. https://doi.org/10.1016/j.ijfatigue.2015.08.006

Monrrabal, G., Bautista, A., Guzman, S., Gutierrez, C., \& Velasco, F. (2019). Influence of the cold working induced martensite on the electrochemical behavior of AISI 304 stainless steel surfaces. Journal of Materials Research and Technology, 8(1), 1335-1346. https://doi.org/10.1016/j.jmrt.2018.10.004

Monteiro, S. N., Nascimento, L. F. C., Lima, É. P., Luz, F. S. da, Lima, E. S., \& Braga, F. de O. (2017). Strengthening of stainless steel weldment by high temperature precipitation. Journal of Materials Research and Technology, 6(4), 385389. https://doi.org/10.1016/j.jmrt.2017.09.001

Nur, S. A. (2016). Steel structures gaining popularity in cities. (Extracted on Dec. 02, 2020). Source: https://dailyasianage.com/news/28068/steel-structuresgaining-popularity-in-cities

Rahman, M. (2019). Curbing air pollution. The Finincia Express. (Extracted on Dec. 02, 2020). Source: https://thefinancialexpress.com.bd/views/views/curbing-airpollution-1577111648

Sanaullah, M., Rahman, J., Ibrahim, I., \& Rahman, M. S. (2019). Behavior of Concrete Filled Stainless Steel Tubular Column Under Axial Loads, MIST Journal of Science and Technology, 7(1), 9-18.

Sungho, P., Noseok, P., \& Jaehoon, K. (2010). A statistical study on tensile characteristics of stainless steel at elevated temperatures. Journal of Physics: Conference Series, 240. https://doi.org/10.1088/1742-6596/240/1/012083

Sutanto, H. (2007). Residual stresses on high-speed milling of hardened steel using CBN cutting tool. Journal Tecknolgi of Media Teknika, 7(2), 1-7.

Tiryakioğlu, M., Hudak, D., \& Ökten, G. (2009). On evaluating Weibull fits to mechanical testing data. Materials Science and Engineering A, 527, 397-399. https://doi.org/10.1016/j.msea.2009.08.014

United Nations (2020). World Economic Situation and Prospects 2020. (Extracted on Dec. 02, 2020). Source: https://www.un.org/development/desa/dpad/publication/world -economic-situation-and-prospects-2020

Wang, H., Shi, Z., Yaer, X., Tong, Z., \& Du, Z. (2019). High mechanical performance of AISI304 stainless steel plate by surface nanocrystallization and microstructural evolution during the explosive impact treatment. Journal of Materials Research and Technology, 8(1), 609-614. https://doi.org/10.1016/j.jmrt.2018.05.010

Wang, Q. G., Apelian, D., \& Lados, D. A. (2001). Fatigue behavior of A356-T6 aluminum cast alloys. Part I. Effect of casting defects. Journal of Light Metals, 1(1), 73-84. https://doi.org/10.1016/S1471-5317(00)00008-0

Weibull, W. (1951). A Statistical Distribution Function of Wide Applicability. Journal of Applied Mechanics, 18, 293-297.

Zeng, H. H., Yan, R., Peng, F. Y., Zhou, L., \& Deng, B. (2017). An investigation of residual stresses in micro-end-milling considering sequential cuts effect. International Journal of Advanced Manufacturing Technology, 91, 3619-3634. https://doi.org/10.1007/s00170-017-0088-5 